\title{
“NÓS PREFERIMOS OBEDECER. É ISSO QUE É NECESSÁRIO ROMPER. SE VOCÊ ROMPER COM O CASTIGO, ROMPE COM A RELAÇÃO DE OBEDIÊNCIA, QUE É O PRINCÍPIO DA RELAÇÃO DE PODER, DE ESTADO E DE SOBERANIA."1
}

\author{
Entrevista com Edson Passetti ${ }^{2}$
}

\section{Revista Malala (RM)}

Nosso tema para a próxima edição da revista são os intelectuais e o debate sobre eles. Então, a nossa primeira pergunta é bem aberta e genérica, mas é importante: como você definiria um intelectual?

\section{Edson Passetti (EP)}

Alguém que tenha coragem de produzir análises que não agradem gregos e troianos, ou seja, alguém que faça do seu ofício alguma coisa voltada para a liberdade. É quando a gente faz da liberdade o nosso oficio, ou seja, não a liberdade enquanto algo a ser alcançado no futuro, uma utopia, uma prática liberal, mas uma prática de liberdade cotidiana. Eu acho que esse é o papel do intelectual hoje, esteja ele onde estiver, seja em uma universidade, em uma organização não governamental, em uma fundação, em um instituto, desempregado principalmente. Não dê as costas para o que está acontecendo, não leia a realidade a partir de um único viés, assuma sempre uma perspectiva de quem resiste. Para mim, o intelectual é isso. Claro, intelectual ao meu gosto, porque você tem outras definições diferentes de intelectual, como a distinção entre o trabalho intelectual e o trabalho manual, que produz vários intelectuais diferenciados: o engenheiro, o administrador, o sociólogo, o literato, etc., e o trabalhador do século XX, o trabalhador manual. Hoje, quando a gente está vivendo um mundo de comunicação eletrônica constante e de entrada dos meios eletrônicos na organização da vida e, inclusive, das empresas, universidades etc., o intelectual precisa conhecer esses meios, precisa saber usá-los e precisa criar vírus dentro desses meios, apesar de nós sabermos que grande parte dos hackers é absorvida como agentes de segurança. Hoje, ser intelectual é muito mais difícil, porque grande parte dos intelectuais convencionais está esperando o momento certo para ser capturada pelas instituições,

\footnotetext{
1 Entrevista presencial realizada em 30/11/2018 com Ariel Finguerut, membro do Conselho Científico da Revista Malala, e Cila Lima, da Comissão Editorial da Revista Malala. O conteúdo da entrevista foi transcrito por Tairini Ayhu Cruz Aparício de Almeida e Fábio Rogério Banin Junior, graduandos em História na Universidade Federal de São Paulo (Unifesp) - Campus Guarulhos. A entrevista foi posteriormente revisada por Cila Lima, da Comissão Editorial da Revista Malala, em 8/3/2019.

2 É professor da Pontifícia Universidade Católica de São Paulo (PUC-SP), doutor em Política pela PUC-SP (1994); é professor livre-docente da PUC-SP desde 2000. Como pesquisador, atua principalmente nos seguintes temas: anarquismo, política, abolicionismo penal, sociedade de controle e Estado na linha de pesquisa Poder, Resistências e Liberdade (fonte: Plataforma Lattes).
} 
pelas empresas, etc. Todos se pronunciam liberais ou todos se pronunciam democratas; melhor dizendo, todos são democratas. Eu não sou! Não é o problema dizer que eu não sou, eu não sou democrata. Não faço parte desse pluralismo que "empastela" direita e esquerda, em que todos competem, segundo espera a racionalidade neoliberal. Competem para desempenhar muito bem a sua função, por isso que todos apreciam a meritocracia, todos apreciam o curriculum lattes, todos apreciam os pequenos grupos "especiais", todos apreciam a noção de elite - todos é uma maneira genérica de dizer, quero dizer, assim, uma grande parte.

\section{RM}

Esse papel subversivo, essa busca pela liberdade isola também, não?

\section{EP}

Não, pode acontecer de seus colegas de trabalho tentarem colocá-lo em um ostracismo. É diferente, não é isolar. É ostracismo. Às vezes você serve de bonequinho interessante, de contestação radical. Deixem lê-lo como queiram, o que os surpreende de uma maneira decisiva é que essas práticas de liberdade regulares produzem, às vezes, situações surpreendentes e que conseguem expressar urgências. Eu me recordo, por exemplo, de junho de 2013. Consideraram durante muito tempo (como sempre, na verdade)... Consideram os anarquistas como outsiders que vivem no mundo da fantasia e da utopia. Quando acontece um junho como o de 2013, as pessoas ficam completamente estarrecidas. Por quê? Primeiro, porque os anarquistas são os primeiros a mostrar que existem " $n$ " forças dentro daquele acontecimento. Inclusive, foram os anarquistas que mostraram primeiro a emergência dessas forças de direita se organizando, se estruturando e que acabaram dando nessa consagração do atual capitão reformado. Foram os anarquistas que mostraram isso. Agora, a reação que os anarquistas tiveram sobre eles foi justamente o quê? Filósofos da USP acusando os anarquistas de fascistas. Essa é a mais contundente: fazendo palestras para a academia de polícia deixando bem claro que os vândalos eram os anarquistas. Alguns filósofos uspianos falaram que os black blocks eram fascistas e não eram. Evidentemente que não eram. Essa é uma forma de luta diferente. Se tem uma coisa que é importante quando se fala da diferença é que o intelectual deve estar atento à diferença. Excluir é muito complicado quando você faz análise. 0 mais difícil, quando você se propõe a ser um pluralista, é perceber todas essas forças, sua intenção, suas ramificações e fluxos e quais diagnósticos delas você pode tirar. É assim que funciona o intelectual: análise e diagnóstico. Agora, chegar e dizer assim: "Ela é vândala e eu sou maravilhoso", ou: "Isso é coisa de direita". Não, não é coisa de direita. A direita se organizou, para além dos movimentos, em partido político - e, quando eu falo "direita" aqui, eu estou falando de nazistas. Se você olhar para a Europa hoje - vocês que trabalham com as religiões sabem disso -, os nazistas todos começaram como organizações da sociedade civil, ilegais, etc. 
e viraram partidos. Veja o caso da Alemanha, o caso da França, etc. Foram perfeitamente assimilados de novo pelo sistema político.

\section{RM}

Estão de terno e gravata, não é?

\section{EP}

Sim, sentando às mesas de negociações e participando das coalizões.

\section{RM}

Esse intelectual que você descreveu...

\section{EP}

Que não é bem um intelectual. Eu estava falando dos anarquistas, o que não é bem um intelectual, porque é o sujeito que está na luta constante.

\section{RM}

Ele muitas vezes compromete aquela ideia romântica de busca pela verdade, autonomia, independência?

\section{EP}

Qual intelectual?

\section{RM}

Os democratas que você descreveu.

\section{EP}

Não, eles são justamente aqueles que postulam a verdade. São eles que se dizem os verdadeiros intelectuais e, como nós sabemos, a verdade não é uma mera distinção entre o falso e o verdadeiro. Existe um conjunto de forças, de enunciados, de confrontos de poder para dizer que algo é verdadeiro. Não é assim categórico, como: "Isso é verdadeiro e ponto final", principalmente quando nós estamos falando de ciências humanas e essas coisas com as quais nós lidamos. Eu sempre gosto de dar um exemplo que pode parecer boçal, mas é bem contundente. Os marxistas diziam que o liberalismo não passava de uma ideologia e que a única ciência verdadeira era o marxismo. Isso teve um efeito histórico maravilhoso. Teve uma revolução, veio a União Soviética, a China, Cuba e outros. Aí, com a reação capitalista e a racionalidade neoliberal, voltou à baila o que? Que o liberalismo é um pensamento científico, fundado na economia política, e que o marxismo é uma ideologia; hoje estão praticamente todos convencidos disso. Grande parte ficou convencida do contrário, principalmente nos anos de 1980. Então, você vê que essas grandes construções, essa disputa pela verdade, é disputa também que envolve os intelectuais que querem 
comandar. É disputa de intelectuais, como se fossem exércitos de intelectuais disputando quem comandará a massa.

Eu não sou massa, mas daqui do outro lado, não sendo nem soldado, é que eu consigo ver quem é o soldado, quem é o general, quem comanda e quais são as relações de proximidade que existem entre esses bandos de intelectuais ou entre esses exércitos de intelectuais - que é muito semelhante às religiões, muito semelhante quanto à organização das próprias religiões. É por isso que mais ou menos todos se interpenetram e a gente vê [isso] hoje em dia como um ecumenismo, é alguma prática recomendável. Você pode ser isso, você pode ser aquilo, mas precisamos nos limpar de fundamentalismo. Fundamentalismo, não. Precisamos ser moderados, na recomendação moderada para a convivência entre as religiões ou no chamado equacionamento de conflito, é o que recomenda o ecumenismo. 0 ecumenismo vai funcionar no âmbito das religiões, no âmbito da política, ou seja, a moderação. Os intelectuais viram moderados. Quando eles viram moderados, o que acontece? Eles são candidatos a cargos, a funcionários de carreira e funcionários de política.

\section{RM}

Mas às vezes, nesse ambiente acadêmico, esse radicalismo não é interessante para a diferenciação?

\section{EP}

É e não é. É o que eu disse a você. No ambiente acadêmico, por exemplo, vou falar a partir de nós do $\mathrm{Nu}$-Sol. ${ }^{3}$ É reconhecido em vários lugares que o Nu-Sol é a primeira grande organização de pesquisadores dentro da universidade que se declaram abertamente anarquistas, abolicionistas penais, etc. No começo, as pessoas olhavam para nós e pensavam: "Que bacana”, "A ovelha negra da família”. Ovelha negra, não; ovelha branca ou preta é ovelha; eu não sou ovelha, não preciso de pastor. Detesto aquela canção da Rita Lee da ovelha negra. E por que negra? Não poderia ser loira? Já é uma coisa que me irrita (risos), poderia ser ovelha albina ou qualquer coisa, mas a ovelha negra é que não presta, não é? As pessoas vão deixando passar. Só quando interessa é que elas vão dizer que é assédio ou é preconceito. Então, nós estávamos sendo vistos assim: "hahahaha", mas fomos fazendo as coisas, pois o melhor a se fazer na vida é não dar bola para arquibancada. Já pensou se os bons jogadores de futebol ficassem ouvindo o que a arquibancada fala para eles durante o jogo? Não conseguiriam jogar bola nunca. Por isso, o grande jogador de futebol esquece a arquibancada e não tem problema em que campo joga, se é no meu campo ou no do adversário - deu para perceber que eu gosto de futebol. Com a passagem do tempo, fomos fazendo publicações. Fomos uns dos primeiros a entrar em publicações eletrônicas com sites, com uso desse equipamento contemporâneo e assim passamos a ser olhados com

\footnotetext{
${ }^{3}$ Núcleo de Sociabilidade Libertária: http://www.nu-sol.org/.
} 
um pouco mais de respeito, ainda que com certa raiva - aqui na universidade é o lugar da vaidade, da ira, do ciúme, do desejo sexual enrustido, das fantasias; universidade é uma ilusão, um lugar bem estranho. Chegou uma hora, no começo desta década, em que eu falei: "Vamos tentar uma coisa bem maluca? Bem de ponta?". Que é o projeto temático Fapesp. Tentamos e ganhamos. A partir daí, as pessoas começaram a ter que nos olhar quase que no mesmo nível. É muito mais fácil você entrar no jogo meritocrático que hoje em dia atrai direita e esquerda para o mesmo procedimento racional. Como anarquistas, eu me lembro de termos passado por uma situação extremamente difícil lá nos anos de 1990, quando os anarquistas mais tradicionais diziam que a gente era anarquista acadêmico sei lá o que é isso. Mas eu sempre imagino que, se você tem alguma prática anarquista para realizar, começa onde você trabalha.

\section{RM}

É possível ser um intelectual anarquista na universidade?

\section{EP}

Eu fui diretor de faculdade aqui. A primeira coisa que fiz quando resolvi me candidatar junto com uma colega... A gente estava vivendo um momento difícil aqui, era final dos anos de 1980 e um contexto fácil. 0 momento fácil é que existiam muitos estudantes anarquistas, principalmente no centro acadêmico de ciências sociais. Eu era coordenador de curso e fizemos uma reforma popular muito interessante, em que, nessa relação dos docentes com os discentes; conseguimos introduzir o anarquismo como uma matéria das ciências sociais. Ele só era tratado como movimento pré-político, essas coisas... Hobsbawm, enfim... Conseguimos entrar. Nós éramos muito jovens, todos aqui. Tinha uma ala mais velha e madura de professores muito inteligentes, muito interessantes, muito irrequietos, que fizeram desta universidade o que ela é, também com a nossa força bem jovem naquela época. E então, nós tínhamos uma relação muito forte, aquela coisa de ímã entre os professores mais maduros e os professores mais jovens. Foi quase que uma ideia de que a faculdade tinha que ser dirigida "por essa rapaziada". Eu não me sentia rapaziada naquela época. Tinha trinta e poucos anos, estava num momento muito interessante. E, na época, minha parceira de direção era uma marxista (mais leve) e eu disse pra ela: "Vamos acabar com isso de diretor e vice-diretor? Vamos fazer uma chapa?". Dessa forma, seria direção da faculdade e vice-direção da faculdade governadas por um conselho formado dentro da faculdade, e o conselho da faculdade e o conselho de professores eram abertos a todo mundo, estudantes... Quem quisesse entrava. Foi bárbaro. Nós fizemos uma gestão interessante. Deixamos a faculdade um pouco louca, pois ninguém sabia quem era o diretor e o vice-diretor. Era "a direção". Ficou meio enlouquecida essa parte, mas fizemos um monte de coisas naquela época. Hoje em dia, praticamente todas acabaram. Fizemos uma revista da faculdade que era vontade de todo mundo e que naquela época não tinha. Depois de um tempo, recebeu até financiamento da Fapesp. Nós criamos o Museu da 
Cultura, que funcionou até dois anos atrás, mas agora está fechado. A universidade não faz nada, acabou abandonando.

\section{$\mathbf{R M}$}

É que estão retrocedendo os financiamentos para as universidades...

\section{EP}

Retrocedendo o financiamento, não. Existe uma opção ideológica mesmo. Acho que a PUC está se voltando mais para o catolicismo. Não que ela tenha perdido, ela já foi um lugar de um catolicismo muito avançado, com a Teologia da Libertação. Agora, ela está mais ajustada, mais moderada também e menos interessante. Está mais difícil para eu viver (risos).

\section{RM}

Estávamos conversando antes e a Cila estudou em Marília e eu [Ariel] estudei em Araraquara. Ambos fizemos ciências sociais e, tanto na experiência dela quanto na minha, o anarquismo não teve espaço. A sociologia sempre foi muito marxista e, inclusive, a Cila mencionou que o lobby de marxistas acabava sobrepondo e impedindo que professores anarquistas passassem pelas seleções.

\section{EP}

Aqui na PUC a gente tinha o Mauricio Tragtenberg, que era um marxista libertário, digamos assim. Depois, com a gente aqui, também vieram juntos a Luzia Margareth Rago, na Unicamp, mas ela já estava instalada; o Silvio Donizetti de Oliveira Gallo, de lá também, já estava instalado; o Ricardo Liper, da Universidade Federal da Bahia, que se projetou; a Maria Olipen, na universidade de Santa Catarina. Nós fomos formando um grupo... Algumas pessoas que se comunicavam e que em determinado momento acharam que era possível, tanto no campo da história, da educação, da filosofia na Bahia ou daqui da PUC, nas ciências sociais. Foi criando um momento possível, mas, como eu estava contando para vocês, os anarquistas mais convencionais nos viam como "anarquistas acadêmicos". Hoje, grande parte deles faz mestrado, doutorado. Às vezes, eu me encontro com eles e digo: "E aí? Quem era o 'anarquista acadêmico'? Você virou esse anarquista acadêmico e está fazendo uma corrida desnecessária, pedindo bolsa, etc.". Porque bolsa não é concessão pedida a ninguém, é dinheiro seu. Quando eu peço [para] um projeto temático, eu não tenho o menor problema em pedir, porque a verba da Fapesp é meu dinheiro coletado de impostos. Ninguém está me dando nada, o Estado não está me dando nada. Eu estou apenas reentrando em um fluxo para retirar parte do que me foi "sequestrado" e não é pouco.

\section{$\mathbf{R M}$}

Roubado talvez... (risos) 


\section{EP}

Vou deixar no sequestro (risos), porque pega, mas eu também vou lá e arrumo um jeito de tirar. Só que eu tenho que entrar no jogo meritocrático para conseguir retirar uma parte disso, mas que a propriedade é um roubo, disso eu não tenho a menor dúvida. Proudhon já dizia isso de uma maneira bastante clara. Claro que ela é roubo. Se não fosse roubo, não existiria capitalismo. As pessoas querem capitalismo sem legalismo, sem corrupção. Até na igreja é assim. Não tem religião que não tenha corrupção: o pastorzinho leva para o canto na salinha do lado, o padre leva para a sacristia, o João de Deus leva agora para o quartinho da roupa branca. Não é possível. Toda estrutura hierárquica é inerente a corrupção e todo regime de trabalho que subordina alguém, idem, é um roubo. Quero nem saber se isso chama mais-valia ou menos-valia. Estou sendo roubado, e isso é preciso deixar claro. 0 salário é apenas uma fantasia dentro desse roubo (risos).

\section{RM}

Um aspecto que eu acho interessante, talvez você possa dizer: há intelectuais ou anarquistas que mudaram de lado, deixaram de ser anarquistas? Porque uma coisa que me incomoda, por exemplo, entre marxistas, é que às vezes eles mudam de lado. É muito comum juventude marxista e vida adulta conservadora; ou, por exemplo, você milita no socialismo e descobre que a União Soviética foi totalitária e se torna antissoviético. 0 Noam Chomsky está fazendo 90 anos e ele diz ser de uma linhagem anarquista. Particularmente, eu também não conheço ninguém que tenha sido anarquista e em algum momento "trocou de lado".

\section{EP}

Eu vou dizer uma coisa: já falei pra vocês que gosto muito de futebol. A única coisa que acho que não muda na vida é time de futebol. 0 resto você pode mudar tudo. Esposa, cachorro, amor, sexo, política, partido, ideologia... Dá para mudar tudo, menos time de futebol (risos). Isso significa que não existe absoluto. Você pode mudar tudo: anarquista que vira marxista, marxista que vira anarquista ou liberal, pode ter tudo. Esse é o mundo em que vivemos. Eu jamais vou cobrar, nem de mim, nem de ninguém, um atestado ideológico. As pessoas podem mudar e mudam. Surpreende-me quando elas vão se tornando cada vez mais à direita. Isso me surpreende. Mas o resto é a realidade que a gente vive.

Eu venho de um mundo em que a ditadura se instalou quando eu tinha 13 anos. Eu já tinha certo discernimento do que era isso. Tinha a família para dizer o que era isso e então passei por várias experiências desse tipo, de saber claramente o que é ser de direita e o que é ser de esquerda, quem é autoritário e está do lado da tortura. Depois aconteceram os travestidos generalizados: todo mundo virou democrata e você pensa que "ainda bem". Eu não entrei nessa jogada. Todo mundo virou democrata, Jarbas Passarinho, todo mundo virou democrata. Dessa forma, esse fluxo de direita-centro-esquerda é muito mais rápido entre as pessoas, então não me surpreende. Pode mudar, todo mundo muda, 
e é bom que mude. Eu sempre digo antes de qualquer coisa: eu sou palmeirense. Não adianta me perguntar se eu sou anarquista ou não sei o quê. Eu sou palmeirense. Estou nem aí que tem um monte de torcida fascista do Palmeiras. Tenho perfeito discernimento, mas eu sou Palmeiras e, do que eu aprendi, essa é a única coisa de que eu não abri mão na minha vida, e a única coisa em que, ao educar os meus filhos, eu fui incisivo foi isso, todos são palmeirenses. 0 que eles vão fazer a partir desse ponto, se foram, são ou serão anarquistas, tudo bem. De direita e centro ninguém é. Meus netos também. Meus filhos estão educando de uma maneira "bacana". Todo mundo é palmeirense e ponto. É isso que nos liga. Depois, as nossas experiências de liberdade. Tem gente que descobre que quer ser mulher com 50 ou 60 anos. Tudo bem. Qual é o problema? Que ótimo. Se isso lhe dá liberdade e o deixa à vontade, se isso não for transformado em uma obrigação identitária para os demais. Odeio identidade, detesto, não me dou bem. Acho reativo defender as coisas por identidade. Então, se quer mudar, desde que seja em função de práticas de liberdade, eu sempre acho muito bom.

\section{RM}

Inclusive porque, às vezes, se você não se posiciona, acaba justificando atos que são injustificáveis, atos de violência.

EP

Eu sempre chamei isso de contraposicionamento. Eu sou a favor do contraposicionamento, porque posicionado todo mundo está, mesmo quando se faz de tonto. Quando alguém fala: "Não sei muito bem" saia fora, porque vem "rolo" (risos). Esse para algum lado vai se jogar. Tinha até uma fantasia interessante entre os analistas de política, de que o PSDB vivia sempre em cima do muro. Olha, eu não acredito nisso, porque em cima do muro você está na fronteira e estar na fronteira significa que um pé anda para cá e um pé anda para lá. Eu não quero andar assim. Eu sou mais Maria Bethânia nessas coisas, você é ou não é. Não tem mais ou menos. Não vou discutir outras identidades, porque não me interessam. Se isso faz parte de uma prática de liberdade e ela dá prazer, então está ótimo. Se a pessoa quer jogar bomba na vitrine da Hermès, joga. Quer atentar contra essas estátuas públicas, aquele negócio reacionário que tem no Ibirapuera? Toda vez que passo por lá, eu penso em como é possível ter isso em um espaço público. Que coisa mais repressiva, mas eu lembro que, uma vez, alguém fez uma pichação e todo mundo se indignou porque era um espaço público, quando, na verdade, ele é todo privatizado. É exorbitante o uso do espaço público pelos interesses privados, pelas realizações privadas. Os anarquistas discutiram muito quando tiveram que optar por algo considerado de terrorista, mas que, na verdade, era de ação direta. Quando colocava bombas nos cafés, por exemplo. 0 café não é público. Se você pegar todos os cafés que foram atingidos pelos anarquistas, eram centros de altas burguesias e financistas. Não tinha nada de espaço 


\section{entrevista}

público ou popular. Você não vai ver uma ação de violência anarquista diretamente onde é público no sentido de uso coletivo.

\section{RM}

Mas não é complicado o uso da violência?

\section{EP}

Complicado é o uso da religião para explodir metrô. Isso, sim, é complicado e eu acho violento. Acho violento. Já não bastava o final da Segunda Guerra com a bomba atômica? Os experimentos da bomba atômica, a apologia da conquista do espaço sideral por meio de medidas de segurança armamentista, isso eu considero extremamente violento. Essa colonização do espaço sideral de uma maneira militar, isso é violento. Essa reação, digamos assim, violenta de protestos, ela é resultante do confronto de forças. Diante de uns "macacos" imensos com cassetete e bombas quer que eu faça o quê? Saia correndo? Eu não sou torcida uniformizada que desafia a polícia para sair correndo. Não sou intelectual juramentado que desacata para sair correndo. Também não acho que ninguém deva ter a disposição para ser mártir ou herói. É uma situação real e imediata de confronto. Então, qual é a violência? A polícia e as Forças Armadas podem usar da violência, têm autorização para usá-la legitimamente contra você. Isso está consagrado na lei, mas a lei não foi feita para todos.

\section{RM}

Os intelectuais, quando justificam uma violência, mesmo que seja revolucionária, não estão também legitimando essa violência, mesmo que seja, por exemplo, anticolonialista?

\section{EP}

Eu não acho, porque, quando a gente pensa em Estado moderno, pensamos nele como monopólio legítimo da força, como Max Weber constatou, assim como todos constataram. Marx e Bakunin também constataram. Ele não inventou que não existe o Estado moderno sem a unificação dos exércitos e sem o monopólio da força. Isso é parte histórica e não pensamento político. É história, e história você muda fazendo. Os liberais querem colocar fim, tipo Fukuyama, nessa possibilidade dinâmica da história.

\section{RM}

Estávamos falando da questão da justificativa da violência, enfim, o tema da violência...

\section{EP}

É inevitável a violência. Nós podemos aqui até nos declarar pacifistas, porque queremos o mínimo de confronto físico. Nas minhas relações eu não tenho isso. Eu sou bem abolicionista penal mesmo. Abolir o castigo em si mesmo, abolir o castigo como uma 
medida, abolir o castigo como prática, abolir o castigo como palavra. Isso nós podemos e, com o tempo, você vai educando seus filhos e eles vão pressionando as escolas a não usarem os dispositivos de castigo. Hoje não se aceita mais o castigo físico, mas o constrangimento ainda ocorre. Ou essa criminalização das condutas. Antes não se aceitava o homossexual e hoje qualquer coisa que você diga é considerada uma conduta homofóbica e considerada crime. Você fica no meio do "tiroteio", porque, se um gay trata o outro de bicha, e você entra na conversa chamando de bicha, já dizem que não pode. Eu penso que se pode abolir essa violência, a penalização, o castigo, a punição.

Isso pode ser abolido imediatamente, você falando para si mesmo, pois toda mudança começa assim. Existimos porque há um externo que está em relação conosco diretamente; não estou falando do psicológico. Essa coisa externa que diz eticamente que você está fora e que não faz parte disso, mas, diante da força organizada do Estado, eu não posso dizer a você que balançarei a bandeira branca ou farei paz e amor, apesar de achar muito interessante tudo isso, porque é uma realidade completamente diferente e a cada vez que nos encontramos é diferente. 0 ano de 2013 foi sensacional, mas tem o outro lado: 0 equipamento da polícia foi totalmente renovado depois de 2013, desde as roupas policiais até os carros e equipamentos, porque eles temem. 0 Étienne de La Boétie tinha uma coisa muito interessante, quase que parodiando o Maquiavel. Maquiavel dizia que o príncipe não é para ser temido em seu limite. Já La Boétie dizia que o príncipe, o rei, o soberano teme o povo. Ele morre de medo, por isso ele precisa de toda essa força, porque ele é menos, é pouco, é minoritário do ponto de vista numérico. Eu moro próximo de um estádio de futebol e uma vez eu estava em casa e ouvi barulhos de tiroteio. Aquele barulho... Eram cinco ou seis policiais contra 200 torcedores do Santos. Eu saí na rua e disse: "Escuta aqui, moçada, ou vocês colocam para correr ou desapareçam". Ficaram todos "meio assim", até os policiais me olharam com espanto (risos). Duzentos contra cinco, vocês ficam correndo deles. Numericamente somos em mais.

\section{RM}

Não pela consciência. Somos maiores pela força e pela quantidade, mas não pela consciência...

\section{EP}

La Boétie tem outra coisa muito boa: nós preferimos obedecer. É isso que é necessário romper. Se você romper com o castigo, rompe com a relação de obediência, que é o princípio da relação de poder, de Estado e de soberania, etc. Acabar com o castigo quando se educam filhos. É necessário acabar com esse negócio, porque você lembra que foi criança e, de fato, a criança é ponto de investimento de saber e é algo político o tempo inteiro na sociedade em que nós vivemos. É preciso pensar na forma de alterar como se vai educar a criança. "Escola sem partido" vai formar um bando de "débeis mentais", é a mudança em cima da criança. Quando você é criança e sente na pele o efeito físico da força 


\section{entrevista}

ou moral, acaba se revoltando. Eu aprendi muito com meus filhos, eles realmente "me passaram uma rasteira", foi ótimo. Tive quatro e deveria ter tido quarenta para ter tanto desconserto. Eu era um idiota que me sentia equilibrado aos 25 anos.

\section{RM}

Quanto a esse tema dos filhos, eu fico pensando que a existência é tão complicada, tão difícil, que a decisão de ter um filho me parece até um ato criminoso (risos).

\section{EP}

(Risos) Pode ser um crime contra a sociedade. É isso mesmo. Para matar essa sociedade, é mesmo. Dessa perspectiva, é. Colocar um basta, um basta na doutrinação. Colocar um serzinho no mundo (...) Produza a liberdade, quero aprender com as suas, quero andar junto com isso se for possível, porque são muito chatos aqueles pais que ficam colados em filhos, querendo ser moderninhos e jovens. 0 que eu quero dizer é que, com essas crianças, a gente pode ser reeducado como adulto no sentido de reaprender a ser livre. As crianças o colocarem contra a parede o fazem rever suas certezas . Não é que ele vai dizer: "Papai e mamãe, vamos fazer uma 'DR'” (risos), mas você vai olhar e perceber o que está fazendo, querendo consciência em uma criança. Para colocar ideia de consciência em uma criança, é necessária força, seja força da astúcia, seja força física. E a criança, também largada a si própria, nasceu e você diz: "Você é livre". Daqui a três dias, você vai ver e tem um cadáver. Nem se alimentar ela consegue sozinha. É uma relação. São essas relações que eu considero coisas decisivas.

\section{RM}

Eu estou aqui com o seu livro Éticas dos Amigos: Invenções Libertárias da Vida e nele você menciona muitos autores pré-socráticos. Tem algum intelectual que você escolheria como influência muito forte para si ou que você olhe como um pensador em que se espelhe e dialogue?

\section{EP}

Engraçado... Nunca ninguém me perguntou isso (risos), nem eu parei para pensar. Eu gosto muito dos pré-socráticos, aquilo que se chama de pré-socráticos. Gosto de trágicos gregos, gosto muito das tragédias gregas e, quando estou em alguma situação embaraçada, sempre vou em casa. Tenho várias delas e fico procurando alguma. Nietzsche eu gosto bastante e leio bastante. Leio bastante Foucault, obviamente Proudhon - já que escrevi uma coletânea com o professor Paulo Resende nos anos de 1980, a convite do Florestan Fernandes, para a Ática sobre Proudhon, gosto do Proudhon, acho interessante. Os anarquistas, de modo geral, eu gosto. Mesmo quando tem certa diferença, que eu acho chato em algumas passagens, meio bobinho, eu gosto. Não gosto do Chomsky. Acho um saco e um oportunista. 


\section{RM}

Você mencionou o Nietzsche. Alguns leem o Nietzsche em uma abordagem antiintelectualista. Como você vê essa ideia anti-intelectual?

\section{EP}

Engraçado, tem umas coisas meio malucas. Com o Nietzsche eu tinha certo preconceito, porque, quando era bem moleque, eu ouvia falar do Nietzsche e do nazismo, na escola. Na minha casa e na família, não, mas isso ficou em mim. Eu tenho verdadeiro pavor de campo de concentração. Não sei se é porque fui criado em uma família de imigrantes em que o impacto da guerra foi muito grande, então essa coisa de campo de concentração eu tenho um monte de livros sobre, estou sempre lendo a respeito disso. Então, Nietzsche era uma coisa meio perdida. Eu comecei a ler naquela linha meio pós-68, mas escondido, porque todo mundo era marxista e eu fiz ciências sociais, então meu curso foi marxismo do começo ao fim. A única deixa que deram foi para o Max Weber; o resto, só o marxismo. Eu li bastante Weber porque comecei a me interessar pelo funcionamento institucional e, no final do curso, comecei a ler Foucault. Nesse ponto, volta o porquê de eu gostar de Nietzsche pelo Foucault, também pelos anarquistas e por um autor que eu havia recusado, que era o Max Stirner, que é forte nesse livro. Nietzsche, Stirner e Foucault são os três caras que eu mais abordo nesse livro. Stirner veio com tudo. Ele é uma leitura não dita, feita pelo Nietzsche. Só o Baumgarten vai dizer depois que isso aconteceu. Sobre o Stirner, tem uma anotação brevíssima feita pelo Henri Lefebvre sobre um seminário que Foucault deu a respeito do Max Stirner. Foucault nunca fala de Max Stirner, mas Foucault é como Nietzsche, nunca diz de onde pegou. Os filósofos, de modo geral, não são como nós que ficamos fazendo nota de rodapé o tempo inteiro; a discussão é outra. São essas pessoas... 0 Kafka para mim é fundamental, é como os trágicos gregos. Quando tenho algum problema, também leio Kafka.

\section{RM}

Kafka durante muito tempo foi retratado como depressivo e obscuro e agora descobriram que a vida pessoal dele não era a obra dele.

EP

Não faço a menor ideia, nunca entrei nesse negócio. Tem uma passagem do Kafka que eu adoro, em um livro do Ricardo Piglia, no qual ele fala de um eventual encontro entre Kafka e Hitler jovem. É sensacional. Eu gosto dessas coisas assim que inventam. Gosto de literatura. A literatura dá liberdade para esses encontros impossíveis, mas, quando tenho problemas ou acho que estou com algum problema, eu leio Kafka também, porque para mim é fundamental. $O$ Castelo eu considero até hoje o melhor livro dele. Um livro que não tem final, só para. É como ver Buñuel ou Almodóvar, que tinham muito isso. Você está no maior pique do filme e pensa: "E agora?" (risos). Parece que deixam com um problema e a 
gente pensa: "Pera aí... Eu não estou aqui para resolver esse problema para você" (risos). Kafka tem muito disso, uma admiração pelos bichos, de compreender os bichos, de não tratar os animais como alguém à parte da existência humana, como a tradição aristotélica. Então, eu tenho algo muito forte por Kafka. Não sei, acho essa coisa do escritor de escrever porque é vital e não para ser publicado... Escreve como um jeito de se transformar. Isso tem no Foucault. Ele transforma escrevendo, com uma urgência. É como os filhos também, eu me transformo com meus filhos. É uma urgência, essa é a prática da liberdade.

\section{RM}

Acho que não poderíamos terminar de forma melhor. Muito obrigado.

EP

Eu que agradeço. Adorei conversar com vocês e essa liberdade que vocês me deram para falar. 